chapter considers the selection and grading of learning tasks, and contains, inter alia, practical examples of activities found in a content syllabus (i.e. a syllabus in which experiential content is derived from a specific subject area, e.g. biology). It is followed by a very practical chapter on selecting and grading objectives.

The final section: "Exploring syllabus design", looks closely at curriculum and syllabus models and their underlying assumptions. The tasks set in this section assist the teacher to examine critically the syllabus he is using in terms of goals, the selection and sequencing of grammatical elements, tasks and activities, and the integration of all components of the syllabus.

Nunan regards it as essential for teachers to engage in a critical appraisal of new ideas and research in their field in order for them to contribute to the curriculum design and development process. Teachers who work through this book, responding to the challenge of the many tasks set, will undoubtedly be in a position to interpret and modify their syllabuses in the process of translating them into action. The author does not merely describe the theories and syllabus types, but subjects them all to critical analysis. Throughout he shows how closely syllabus design and method are related, design being seen as concerned essentially with the selection and grading of content, while methodology is concerned with the selection of learning tasks and activities. He suggests that with the advent of communicative language teaching, the distinction between content and tasks is difficult to sustain.

For the language teacher who is aware of shortcomings in the syllabus he is using, I heartily recommend this book, for it will enable him to grasp the issues basic to syllabus design, expose him to viable alternatives, and assist him to modify or interpret his syllabus in such a way as to best suit the needs of his students. For the curriculum designer this is essential reading. The subject matter is comprehensively and lucidly dealt with, the tasks are practical and relevant, and the reader is given a clear overview of current thinking and research in this field.

Language syllabus design cannot be divorced from $\mathrm{L}_{2}$ teaching, therefore this publication can go a long way towards helping teachers revitalize their thinking and planning, and towards promoting a more effective approach to $L_{2}$ classroom instruction.

\title{
The Oxford English Dictionary (Second Edition)
}

\section{Oxford: Oxford University Press, 1989. (Twenty volumes: $22000 \mathrm{pp}$.)}

In 1857, the Philogical Society decided that all existing English dictionaries were deficient and that the whole language from Anglo-Saxon times onward needed to be re-examined. The complexity of the language and its constantly evolving nature required a work of much larger dimensions than had been originally envisaged, and it was only 71 years later, in 1928, that the first edition of The Oxford English Dictionary was published, embracing 15488 pages and over 40000 words and phrases. Supplements were added to this edition at regular intervals, in order to incorporate the most recent words and meanings.

In 1984 OUP undertook to integrate and update the OED and its supplements in the form of its second edition, co-edited by J.A. Simpson and E.S.C. Weiner. This mammoth task was completed in 1989 and the result is probably the world's most authoritative and comprehensive dictionary - the greatest work in lexicography ever undertaken. This twenty 
volume set boasts the following features:

- definitions for more than a half million words with more than 2,4 million illustrative quotations;

- 5000 new words and meanings added;

- a completely new design to present the material in its most accessible form;

- it uses the International Phonetic Alphabet;

- it covers the entire English vocabulary since $1150 \mathrm{AD}$, including the most recent words reflecting linguistic, social and technological developments;

- it reflects the international nature of English, including words drawn from other languages;

- in addition to an authoritative definition of each word, its variant spellings are provided, as well as extensive treatment of etymology, details of area of usage, and a selection of quotations illustrating its use from its first recorded usage to an appropriate modern example.

The appeal of this new edition of the OED should prove to be universal. Not only linguists, but historians, philosophers and lawyers should find it a research tool of inestimable value, as should students of media studies, classical studies, medicine and the sciences. In it, modern words such as "soap opera", "yappie", "skinny dip" and "trekkie" are featured alongside words belonging to the most complex technological fields.

This second edition of the OED is the triumphant culmination of 132 years of dedication and thorough research. However, its price (R7 850 for the twenty volume set) is likely to place it beyond the means of the average library. On the other hand, as a work of authority, it clearly has no equal. The Times calls it "the greatest English book this century", while Anthony Burgess remarks: "Nothing is omitted, however slangy or scabrous or high-tech". Times Educational Supplement declares that "it must rank high among the wonders of the world of learning" and that it is "one of the greatest books published since the invention of printing". Oxford South Africa has reported that, despite its price, the set is in demand, and when one considers that the massive first volume is devoted only to the letter $A$ and half the $\mathrm{B}$ 's, it is clear that this dictionary makes all others redundant.

\section{J.J. Swartz}

